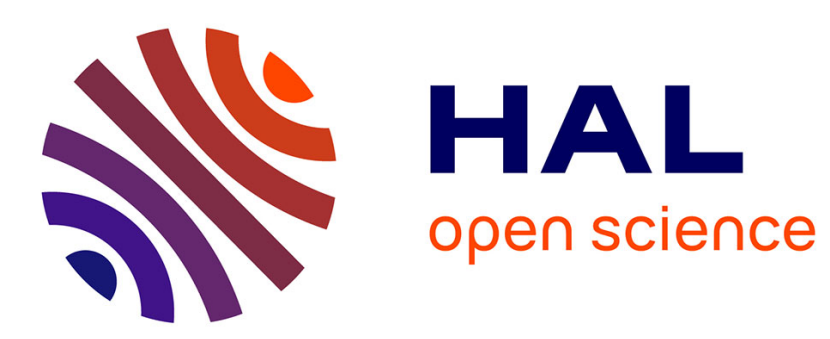

\title{
H-G Diagram Based Rotor Parameters Identification for Induction Motors Thermal Monitoring
}

\author{
Mohamed-Saïd Naït-Saïd, Mohamed Benbouzid
}

\section{To cite this version:}

Mohamed-Saïd Naït-Saïd, Mohamed Benbouzid. H-G Diagram Based Rotor Parameters Identification for Induction Motors Thermal Monitoring. IEEE Transactions on Energy Conversion, 2000, 15 (1), pp.14-18. hal-01052442

\section{HAL Id: hal-01052442 \\ https://hal.science/hal-01052442}

Submitted on 26 Jul 2014

HAL is a multi-disciplinary open access archive for the deposit and dissemination of scientific research documents, whether they are published or not. The documents may come from teaching and research institutions in France or abroad, or from public or private research centers.
L'archive ouverte pluridisciplinaire HAL, est destinée au dépôt et à la diffusion de documents scientifiques de niveau recherche, publiés ou non, émanant des établissements d'enseignement et de recherche français ou étrangers, des laboratoires publics ou privés. 


\title{
$H-G$ Diagram Based Rotor Parameters Identification for Induction Motors Thermal Monitoring
}

\author{
Mohamed Saïd Naït Saïd ${ }^{*}$ and Mohamed Benbouzid, Senior Member, IEEE \\ University of Picardie "Jules Verne" \\ 7, Rue du Moulin Neuf, 80000 Amiens, France \\ "On Leave from the University of Batna, Algeria
}

\begin{abstract}
In this paper, an effective on-line method for induction motor parameter identification, especially rotor parameters, based on the $H-G$ diagram is presented for motor thermal monitoring purpose. The $H-G$ diagram is established from the analysis of the induction motor measurement of active and reactive power consumption for each operating point. Computer simulations and experimental tests, carried out for a 4-kW four-pole squirrel cage induction motor, provide an encouraging validation of the proposed thermal monitoring technique. The process should be refined for a possible industrial application.
\end{abstract}

Keywords: Induction motor, $H-G$ diagram, identification, rotor parameters, thermal monitoring.

\section{INTRODUCTION}

Because of the requirement that induction motors operating in locations which can be exposed to flammable or explosive atmospheres must operate below the autoignition temperature of the gaseous mixture, the accurate determination of the rotor temperature is critical. However, one obstacle appears to be the difficulties in accessing information, particularly, from the rotor while the induction motor is in normal operation. Certainly the availability of continuous temperature profile across the rotor will contribute much to comprehensive condition monitor.

It is well known that numerous modern electrical motors are often working at their rated point and temporary with overload cycles. Therefore, it becomes necessary to protect and to monitor the motor winding temperature against damage by overheating [1-2]. Conventionally and in some cases, this protection is achieved by simple schemes which permit to detect when the Joule effect $\left(i^{2} t\right)$ exceeds a certain critical values. This can be obtained, for example, by means of universal technique like thermal sensor located at the stator slots.

The actual trends for thermal monitoring of an induction motor is achieved without thermal and mechanical sensors. Parameters presently monitored on induction motors include terminal voltage, current and rotor speed. Recently, much attention has been given to the identification of instantaneous value of the rotor parameters, especially the rotor resistance which leads to sufficient information on the rotor temperature. So far, several approaches have been presented [3-9].

This paper describes a new method of rotor parameters identification based on the real-time analysis of the induction motor active and reactive power consumption acquisition. This method is based on the so-called $H-G$ diagram [10], allowing one real-time processing of the induction motor state saturation and temperature for each operating point. The distinct features of the proposed approach lies in its simplicity and quite accuracy.

\section{THE $H$ - $G$ DIAGRAM PRINCIPLE}

An induction motor can be represented by the following differential equations (written in complex form) in $\alpha-\beta$ axes fixed in the stator.

$$
\begin{aligned}
& \overline{V_{s}}=\left(R_{s}+s L_{s}\right) \overline{I_{s}}+s M \overline{I_{r}} \\
& 0=\left(R_{r}+(s-j \omega) L_{r}\right) \bar{I}_{r}+(s-j \omega) M \overline{I_{S}} .
\end{aligned}
$$

Where

$$
\begin{array}{lll}
\bar{V}_{s} & =\quad \text { complex stator voltage } \\
\overline{I_{s}}\left(\bar{I}_{r}\right) & =\quad \text { complex stator (rotor) current } \\
R_{s}\left(R_{r}\right) & = & \text { stator (rotor) resistance } \\
L_{s}\left(L_{r}\right) & = & \text { cyclic stator (rotor) inductance } \\
M & = & \text { cyclic mutual inductance stator-rotor } \\
\omega & = & \text { rotor frequency } \\
s & = & \text { time derivative operator } \\
j & =\quad j=\sqrt{-1} .
\end{array}
$$

Note that all rotor parameters and variables are referred to the stator side. 
In quasi-steady state, the $s$-operator becomes $j \omega_{s}$, where $\omega_{s}$ is the supply frequency. Then, (1) and (2) are modified as follows.

$$
\begin{aligned}
& \bar{V}_{s}=\left(R_{s}+j \omega_{s} L_{s}\right) \bar{I}_{s}+j \omega_{s} M \bar{I}_{r}, \\
& 0=\left(R_{r} \frac{\omega_{s}}{\omega_{s l}}+j \omega_{s} L_{r}\right)+j \omega_{s} M \bar{I}_{s},
\end{aligned}
$$

where $\omega_{s l}=\omega_{s}-\omega$ is the slip frequency.

From (3) and (4), we can express the complex input impedance.

$\overline{Z_{i n}}=\frac{\bar{V}_{s}}{\bar{I}_{s}}=R_{s}+\omega_{s} G\left(\omega_{s l}\right)+j \omega_{s} H\left(\omega_{s l}\right)$,

where

$$
\begin{aligned}
& G\left(\omega_{s l}\right)=\frac{M \omega_{s l} R_{r}}{R_{r}^{2}+L_{r}{ }^{2} \omega_{s l}{ }^{2}} M, \\
& H\left(\omega_{s l}\right)=L_{s}-\frac{M^{2} \omega_{s l}{ }^{2}}{R_{r}{ }^{2}+L_{r}{ }^{2} \omega_{s l}{ }^{2}} L_{r} .
\end{aligned}
$$

The $G\left(\omega_{s l}\right)$ and $H\left(\omega_{s l}\right)$ functions have inductance dimension and can represent, with a quite good approximation, respectively, the active power consumption, generating the motor torque and the reactive power consumption, generating the magnetization flux. Furthermore, for a given sinusoidal stator supply, corresponding to a given saturation state, the $G\left(\omega_{s l}\right)$ and $H\left(\omega_{s l}\right)$ functions vary together describing a circle in the so-called $H-G$ plane with the load variation as illustrated by Fig. 1 [4]. This circle is graduated with the slip frequency increasing from the pure synchronous point $H_{0}$ to the infinite slip frequency point $H_{\infty}$. These two points are theoretical ones and they could be obtained by a circular extrapolation once the experimental circle is plotted.

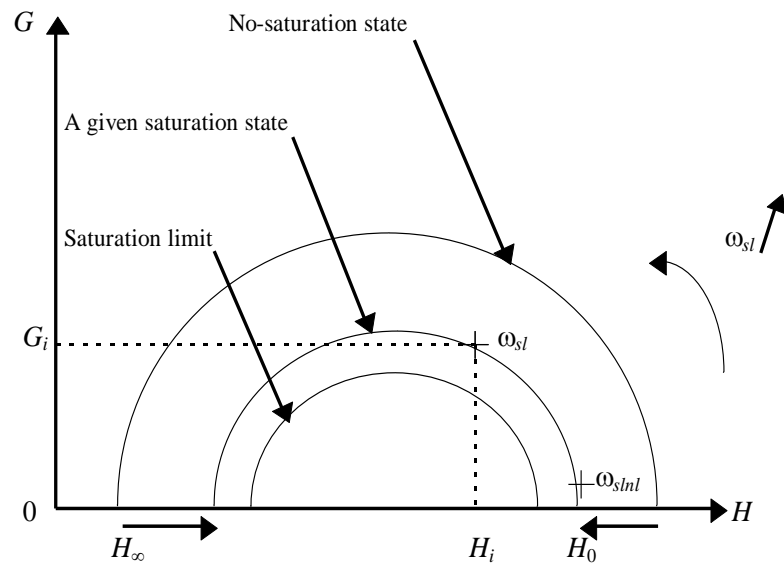

Fig. 1. The $H-G$ diagram.
Generally, these two points correspond, respectively, to a fully loaded motor, with the slip frequency $\omega_{s \ln l}$ (" $n l$ ": no load) and to any other load, with the slip frequency $\omega_{s l}$. Therefore, one can obtain simultaneously the cyclic stator inductance $L_{s}$ and the total leakage coefficient $\sigma$ as follows.

$L_{s}=H_{0}$,

$\sigma=\frac{H_{\infty}}{H_{0}}$

\section{III. $H$ - $G$ DIAGRAM BASED ROTOR PARAMETERS IDENTIFICATION}

\section{A. Saturation Effect}

Assuming that $\sigma$ is quite small such as $H_{\infty} \approx 0$, circle diameters become directly a function of the stator flux $\Phi_{s}$ and then a function of the induction motor saturation state, as it is shown by (10).

$H_{0}=L_{S} \cong \frac{\Phi_{s n l}}{I_{s n l}} \approx \frac{V_{s n l}}{I_{s n l} \omega_{s}}$

When the flux leakage increases with the machine saturation state, the $\left(H_{\infty}, 0\right)$ point moves at the right of the $H$ axis [10-11]. $H_{0}$ fluctuates with the machine saturation state making the $\left(H_{0}, 0\right)$ point moving at the left of the $H$-axis, when the stator flux $\Phi_{s}$ increases. Figure 2 shows then the $H_{0}$ fluctuations versus the induction motor saturation state.

\section{B. Identification Procedure}

The stator voltage and current $\alpha-\beta$ components are obtained by Concordia transformation. The active power consumption $P$ and the reactive power consumption $Q$ are then given by the following equations.

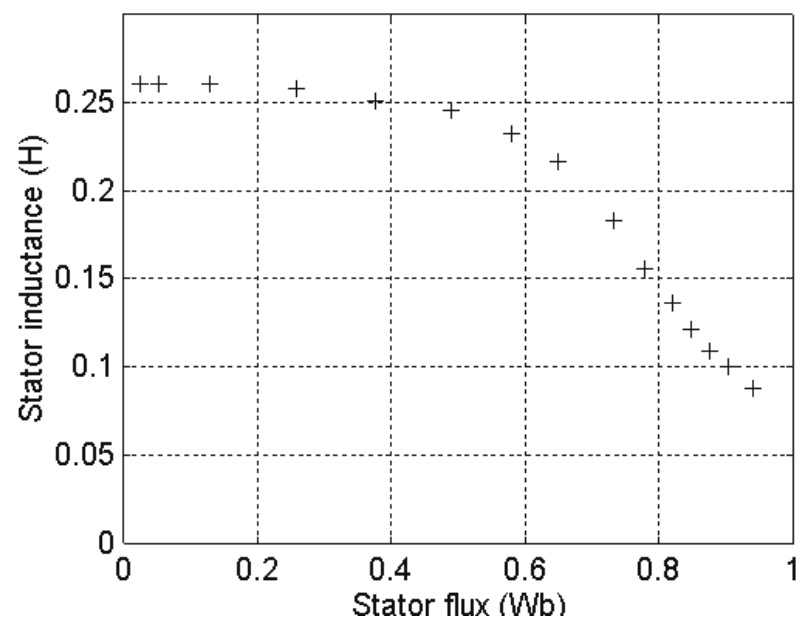

Fig. 2. Experimental magnetization characteristic. 
$P=\overline{V_{s}} \bullet \bar{I}_{s}=v_{s \alpha} i_{s \alpha}+v_{s \beta} i_{s \beta}$,

$Q=\bar{V}_{s} \times \bar{I}_{s}=v_{s \alpha} i_{s \beta}-v_{s \beta} i_{s \alpha}$.

Therefore, for each induction motor operating point (with " $i$ " index $), H\left(\omega_{s l}\right)$ and $G\left(\omega_{s l}\right)$ are given by

$G_{i}=G\left(\omega_{s l}\right)=\frac{1}{\omega_{s}}\left(\frac{P}{I_{s}^{2}}-R_{s}\right)$,

$H_{i}=H\left(\omega_{s l}\right)=\frac{Q}{\omega_{s} I_{s}^{2}}$,

where

$I_{s}^{2}=i_{s \alpha}^{2}+i_{s \beta}^{2}$

The stator flux modulus can be deduced from terminal signals with a known stator resistance. Then the magnetization characteristic $H_{0}=H_{0}\left(\Phi_{s}\right)$, given in Fig. 2, allows the determination of the cyclic inductance $L_{s}$. Moreover, knowing the $\left(H_{i}, G_{i}\right)$ points, one can perform an online computation of the $H-G$ circle position. Consequently the total leakage coefficient $\sigma$ is obtained, according to (9), from the plotted circle. Moreover, one can compute the rotor time constant $\tau_{r}$ using (6) and (7).

$\tau_{r}=\frac{L_{r}}{R_{r}}=\frac{L_{s}-H\left(\omega_{s l}\right)}{\omega_{s l} G\left(\omega_{s l}\right)}=\frac{H_{0}-H_{i}}{\omega_{s l} G_{i}}$.

Considering an equitable share of the flux leakage, the rotor resistance could then be deduced from the following equation [12].

$$
R_{r}=\frac{G_{i}}{1-\frac{H_{i}}{H_{0}}} \omega_{s l} .
$$

It should be noticed that rotor resistance is identified with a real rotor frequency. This allows us to overcome the skin effect.

The mutual inductance $M$ can be expressed, according to $\sigma$ definition.

$$
M=H_{0} \sqrt{1-\frac{H_{\infty}}{H_{0}}}
$$

The proposed identification procedure is illustrated by Fig. 3

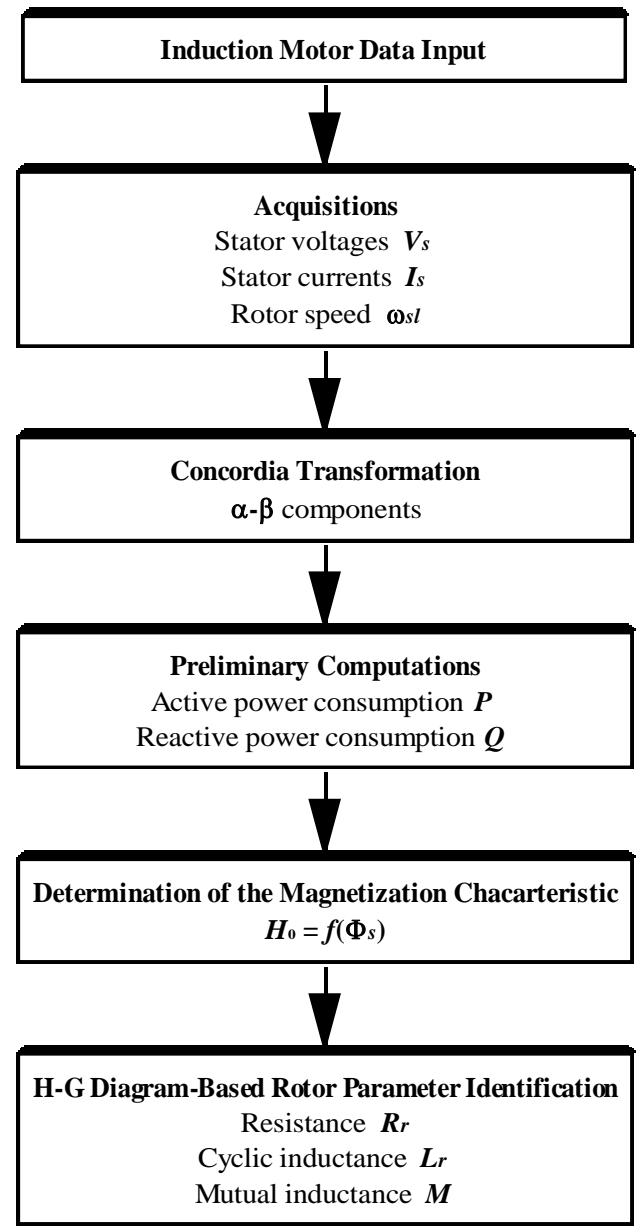

Fig. 3. The proposed rotor parameter identification technique.

\section{Stator Resistance Variation Effect}

In the proposed identification method, the stator resistance is off-line determined by a classical dc-test. For a normal operating induction motor, one have

$G\left(\omega_{s l}\right) \omega_{s}>R_{s}$.

Hence, the stator resistance has not big sensitive on the rotor parameter determination. It is sufficient to take its rated value without any correction. However, it should be noticed that in general the stator resistance is corrected for operating temperature [IEEE 112]. Numerical simulations have been carried out to illustrate the stator resistance variation effect, where the real rotor resistance is simulated by the following exponential profile intended to cover the temperature effect [9].

$R_{r}=1.25-0.35 e^{-t}$

The real stator resistance is deduced from [13].

$R_{s}=k R_{r}$, 
where

$k=\frac{R_{s n}}{R_{r n}}$

$R_{s n}$ and $R_{r n}$ are the rated values of the stator and rotor resistance as given by the induction motor manufacturer.

The estimated error on the identified rotor resistance, with and without taking into account the thermal effect on the stator resistance, is about $2 \%$ as illustrated by Fig. 4.

\section{INDUCTION MOTOR THERMAL MONITORING}

\section{A. The Experimental Set Up}

The proposed rotor parameter identification technique has been tested on a 4-kW squirrel cage induction motor with a dc generator coupled on its shaft. It is then used for the induction motor thermal monitoring. Figure 5 shows a view of the experimental set up.

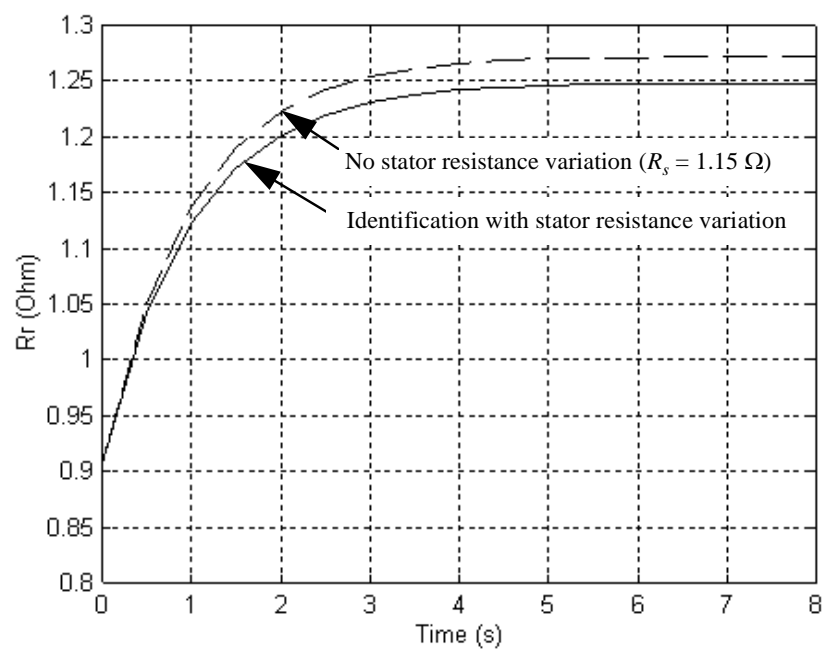

Fig. 4. Stator resistance effect on the rotor resistance identification.

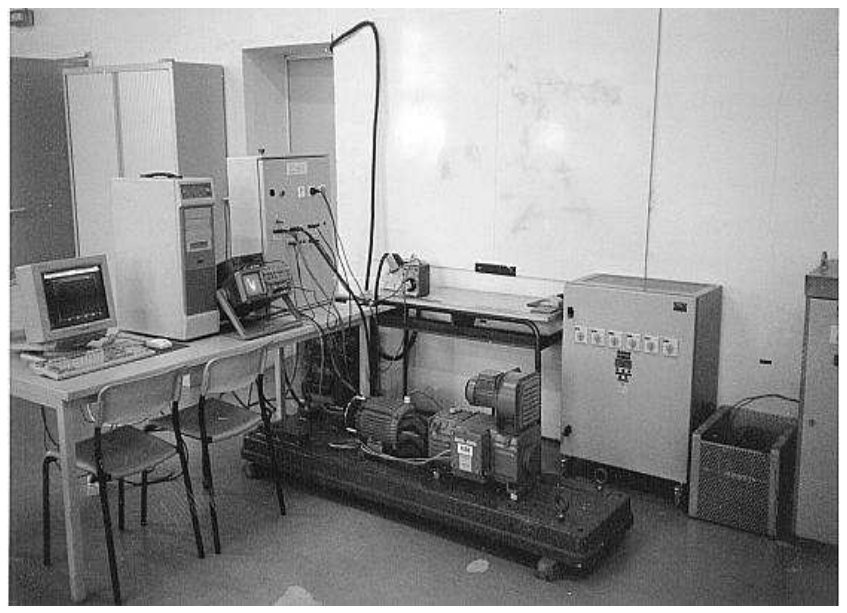

Fig. 5. The experimental set up.

\section{B. Experimental Results}

Figure 6 shows experimental results of the rotor resistance identification for a load corresponding to $1440 \mathrm{rpm}$, where each curve corresponds to a resistance identification, during 1 $\mathrm{s}$, done at 0,60, 240 and $300 \mathrm{~min}$ in order to show the thermal effect on the rotor resistance. It should be noticed that the computed data are low-pass filtered with a time constant equals to $50 \mathrm{~ms}$.

The thermal effect on the rotor resistance is clearly illustrated by Figs. 7 and 8 . In fact, the steady-state rotor resistance, identified every $5 \mathrm{~min}$, is compared to the steadystate temperature sensed with a diode-based thermal sensor placed inside the stator winding, for a total of 4 hours induction motor operating time. In each case, it is found that the thermal time constant is approximately the same and of about 1 hour. The identification process could therefore be considered quite satisfactory.

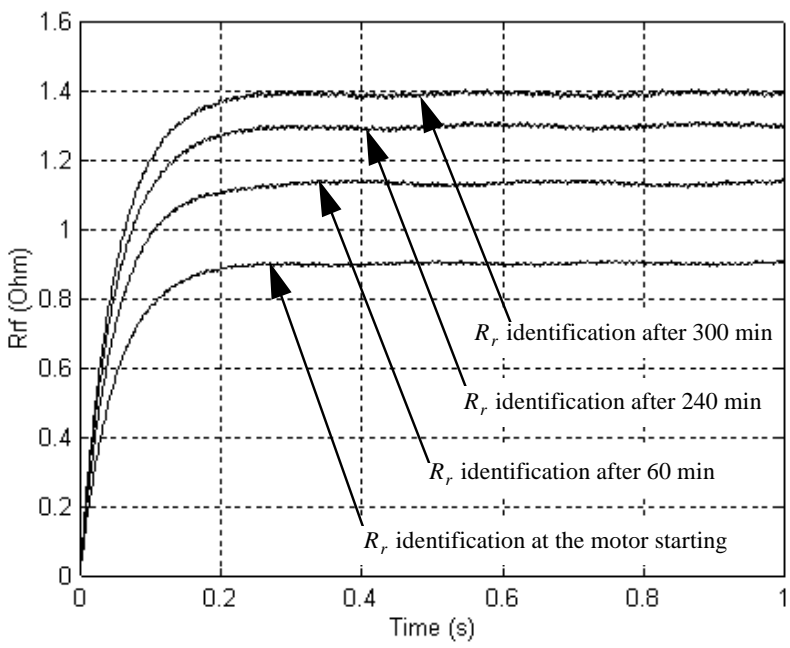

Fig. 6. Specific rotor resistance identification at $1440 \mathrm{rpm}$.

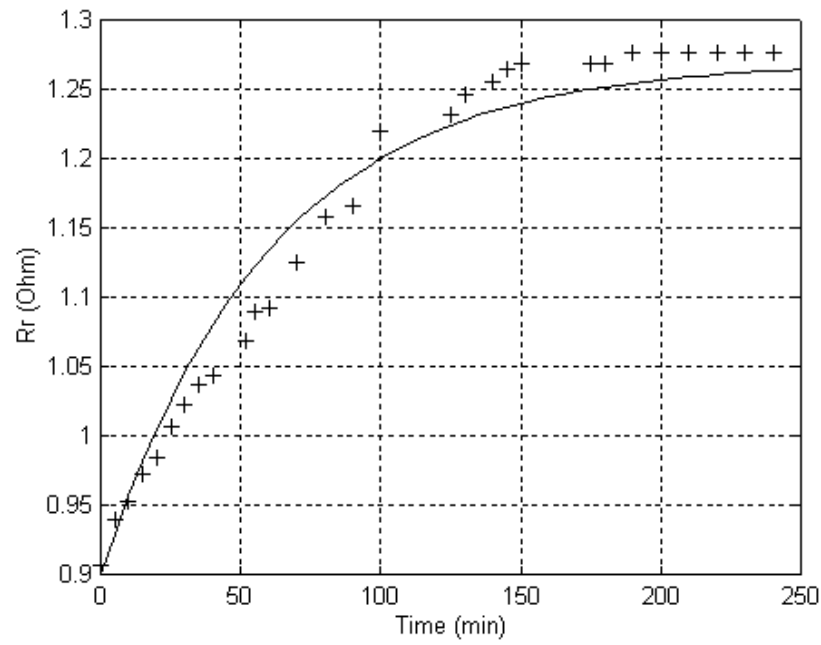

Fig. 7. Rotor resistance identification at $1440 \mathrm{rpm}$. ("- " interpolated curve, "+ +" experimental curve) 


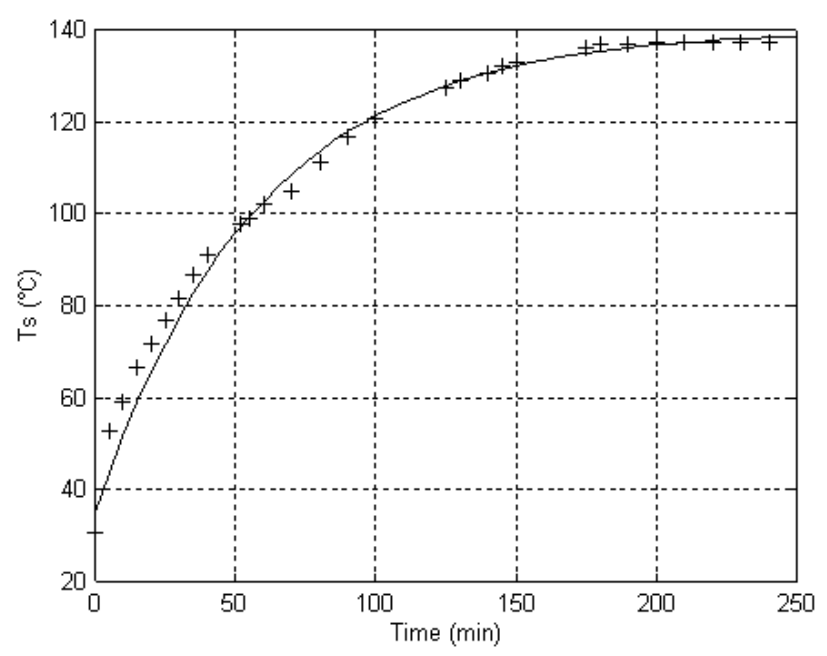

Fig. 8. Measured temperature at $1440 \mathrm{rpm}$. (“-” interpolated curve, "+ +" experimental curve)

It should be noticed that Fig. 8 illustrates the stator winding temperature. In fact, the French Electricity Board (EDF) states that the rotor temperature is about $10^{\circ} \mathrm{C}$ greater than the stator one [9], [14]. Using this approach, one can easily estimate the rotor winding temperature.

Experimental tests have been also carried out to verify the validity of (18). In fact, Fig. 9 clearly shows that the mutual inductance is well identified during the 4 hours motor operation and it is not altered by any thermal effect.

It is easy to monitor the rotor temperature from its resistance identification and then its temperature dependence, which is given by

$$
R=R_{0}(1+\alpha \Delta T)
$$

where $R_{0} \quad=$ resistance at $25^{\circ} \mathrm{C}$

$\alpha=$ resistance temperature coefficient

$\Delta T=$ temperature increase.

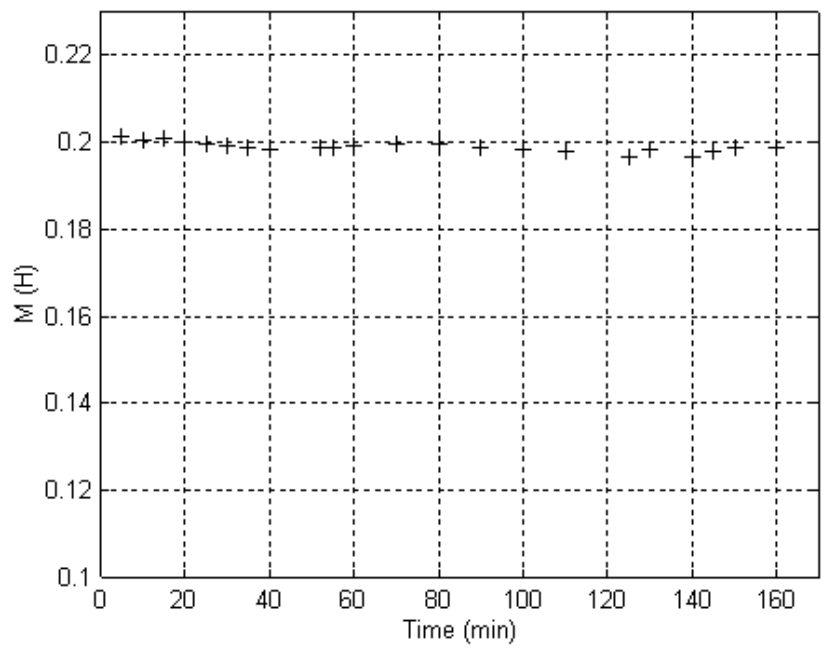

Fig. 9. Mutual inductance identification at $1440 \mathrm{rpm}$.
Using this equation and Fig. 7, the temperature gradient is easily calculated. In fact, it is about $105^{\circ} \mathrm{C}$. This value is approximately equal to the experimental temperature increase inside the induction motor as it is deduced from Fig. 8, which is about $110^{\circ} \mathrm{C}$.

\section{Discussion}

The above simulation and experimental results comparisons have to be refined so as to increase the method reliability. In fact, the EDF statement certainly would not apply to enclosure or design, especially NEMA design D machines with $8-13 \%$ slip.

\section{CONCLUSION}

The $H$ - $G$ diagram method shows that it is possible to determine the induction motor parameters taking into account its saturation and temperature state. In this case, the rotor resistance is identified with a real rotor frequency to overcome the skin effect. In fact, with a classical locked rotor test, this parameter is given with a rotor frequency equals to the stator one.

Computer simulations and experimental tests, carried out for a $4-\mathrm{kW}$ four-pole squirrel cage induction motor, provide an encouraging validation of the proposed thermal monitoring technique. In fact, it seems that the given induction motor temperature information is quite improved using the $\mathrm{H}-\mathrm{G}$ diagram method. However, the thermal monitoring process should be refined so as to increase the method reliability which will lead to a potential industrial application.

APPENDIX RATED DATA OF THE TESTED INDUCTION MOTOR

\begin{tabular}{llll}
\hline \multirow{2}{*}{ Rated values } & Power & 4 & $\mathrm{~kW}$ \\
& Frequency & 50 & $\mathrm{~Hz}$ \\
& Voltage $(\Delta / \mathrm{Y})$ & $220 / 380$ & $\mathrm{~V}$ \\
& Current $(\Delta / \mathrm{Y})$ & $15 / 8.6$ & $\mathrm{~A}$ \\
& Speed & 1440 & $\mathrm{rpm}$ \\
& Pole pair $(p)$ & 2 & \\
Rated parameters & $R_{s}$ & 1.150 & $\Omega$ \\
& $R_{r}$ & 1.100 & $\Omega$ \\
Constants & $l$ & 0.013 & $\mathrm{H}$ \\
& $M$ & 0.203 & $\mathrm{H}$ \\
& $\alpha$ & 0.004 & $1 /{ }^{\circ} \mathrm{C}$ \\
& $J$ & 0.042 & $\mathrm{~kg} \cdot \mathrm{m}^{2}$ \\
& $f$ & 0.032 & $\mathrm{IS}$ \\
\hline
\end{tabular}

\section{ACKNOWLEDGMENTS}

The authors wish to acknowledge the effort of Dr. Benbouzid former students R. Maljonis and D. Diemoz on the stator winding thermal sensor realization. The valuable suggestions and comments made by the reviewers are also acknowledged. 


\section{REFERENCES}

[1] D.A. Paice, "Motor thermal protection by continuos monitoring of winding resistance," IEEE Trans. Industrial Electronics \& Control Instrumentation, vol. 27, n³, August 1980, pp. 137-141.

[2] M. Rioual, "Presentation of a system for the improvement of the on-line thermal monitoring on $900 \mathrm{MW}$ turbogenerators for predictive maintenance purposes," IEEE Trans. Energy Conversion, vol. 12, n², June 1997, pp. 157-165.

[3] F. Loeser and P.K. Sattler, "Identification and compensation of the rotor temperature of ac drives by an observer," IEEE Trans. Industry Applications, vol. 21, N.6, November 1985, pp. 1387-1393.

[4] E.C. Anderson and T. Vetter, "Parameter identification and on-line rotor temperature monitoring of ac squirrel cage motors," Proceedings of the 1988 International Conference on Electrical Machines, Pisa (Italy), September 1988, pp. 251-256.

[5] P. Mellor and D. Turner, "Real-time prediction of temperatures in an induction motor using a microprocessor," Electric Machines \& Power Systems, vol. 15, 1988, pp. 333-352

[6] R. Krishnan and A.S. Bharadwaj, "A review of parameter sensitivity and adaptation indirect vector controlled induction motor drive systems," IEEE Trans. Power Electronics, vol. 6, n 4, October 1991, pp. 693-703.

[7] H. Nestler and P. Sattler, "On-line estimation of temperatures in electrical machines by an observer," Electric Machines \& Power Systems, vol. 21, 1993, pp. 39-50.

[8] S.I. Moon and A. Keyhani, "Estimation of induction machine parameters from standstill time domain data," IEEE Trans. Industry Applications, vol. 30, n6, November-December 1994, pp. 1609-1615.

[9] R. Beguenane and M.E.H. Benbouzid, "Induction motors thermal monitoring by means of rotor resistance identification', Proceedings of the 1997 IEEE Electrical Machines and Drives Conference, Milwaukee, Wisconsin (USA), May 1997, pp. TD2-4.1-4.3.

[10]M.S. Naït Saïd, R. Abdessemed and M.E.H. Benbouzid, "Squirrel-cage induction motor parameters identification by means of the $\mathrm{H}-\mathrm{G}$ diagram," Proceedings of the 1996 Tunisian Conference of Electrical Engineering, Hammamet (Tunisia), November 1996, pp. 134-145.

[11] N.R. Klaes, "Parameter identification of an induction machine with regard to dependencies on saturation," IEEE Trans. Industry Applications, vol. 29, n6, November-December 1993, pp. 1135-1140

[12]P.C. Krause, O. Wasynczuk and S.D. Sudhoff, Analysis of Electric Machinery, Piscataway: IEEE Press, 1995.

[13]H. Kubota, K. Matuse and T. Nakano, "DSP-based speed adaptive flux observer of induction motor," IEEE Trans. Industry Applications, vol. 29, n², March-April 1993, pp. 344-348.

[14] M. Dessoude, Electricité de France (EDF), R\&D Division, Electrical Equipment Department (France), personal communication, June 1994.

\section{BIOGRAPHIES}

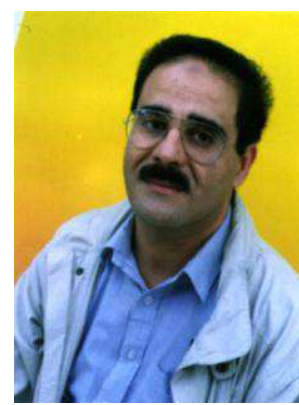

Mohamed Saïd NAIT SAID was born in Batna, Algeria, on September 15, 1958. He received the B.Sc. degree in Electrical Engineering, in 1983, from the National Polytechnic Institute of Algiers, Algeria and the M.Sc. degree in Electrical and Computer Engineering, in 1992, from the Electrica Engineering Institute of Constantine University, Algeria. After graduation, he joined the University of Batna, Algeria, where he is a Teaching Assistant at the Electrical Engineering Institute. M.S. Naït Saïd is actually working towards a Ph.D. thesis on the control of induction motors in the University of Picardie "Jules Verne" at Amiens, France.

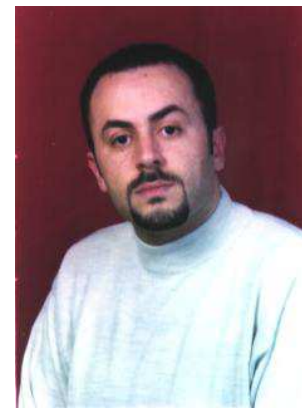

Mohamed El Hachemi BENBOUZID (S'92M'94-SM'98) was born in Batna, Algeria, in 1968. He received the B.Sc. degree in Electrical Engineering, in 1990, from the Electrical Engineering Institute of Batna University, Algeria; the M.Sc. and Ph.D. degrees both in Electrical and Computer Engineering, from the National Polytechnic Institute of Grenoble, France, in 1991 and 1994 respectively. After graduation, he joined the University of Picardie "Jules Verne", France, where he is an Associate Professor of Electrical and Computer Engineering at the Professional Institute of Amiens. His current research interests include electric machines and drives, computational of electromagnetics, and electromechanical actuation, as well as techniques for energy savings. Dr. Benbouzid is a member of the IEEE Industrial Electronics, Industry Applications, Power Engineering, and Magnetics Societies, and the French Electrotechnical and Electronic Association (SEE). He is particularly active in the IEEE Power Engineering Society Working Group on Motor Maintenance and Failure Analysis of the Induction Machinery Subcommittee of the Electric Machines Committee (phone +33 $322282 \quad 76 \quad 80, \quad$ Fax $+33 \quad 3 \quad 22 \quad 82 \quad 78$ 22, e-mail m.benbouzid@ieee.org) 